\title{
Post-fatigue fracture resistance of metal core crowns: Press-on metal ceramic versus a conventional veneering system
}

\author{
M$^{a}$ Fernanda Solá-Ruiz ${ }^{1}$, Rubén Agustín-Panadero ${ }^{2}$, Carlos Campos-Estellés ${ }^{3}$, Carlos Labaig-Rueda ${ }^{4}$
}

${ }^{1}$ DDS, PhD, MD, Adjunct Lecturer, Department of Buccofacial Prosthetics. Faculty of Medicine and Dentistry, University of Valencia, Spain

${ }^{2} \mathrm{DDS}, \mathrm{PhD}$, Associate Lecturer, Department of Buccofacial Prosthetics. Faculty of Medicine and Dentistry, University of Valencia, Spain

${ }^{3}$ DDS, Collaborator Lecturer, Department of Buccofacial Prosthetics. Faculty of Medicine and Dentistry, University of Valencia, Spain

${ }^{4}$ DDS, PhD, MD, Senior Lecturer, Department of Buccofacial Prosthetics. Faculty of Medicine and Dentistry, University of Valencia, Spain

Correspondence:

Unidad de Prostodoncia y Oclusión

Edificio Clínica Odontológica

C/ Gascó Oliag, $N^{o} 1$

46010 Valencia

Spain

m.fernanda.sola@uv.es

Received: 21/12/2014

Accepted: 05/02/2015
Solá-Ruiz MF, Agustín-Panadero R, Campos-Estellés C, Labaig-Rueda C. Post-fatigue fracture resistance of metal core crowns: Press-on metal ceramic versus a conventional veneering system. J Clin Exp Dent. 2015;7(2):e278-83.

http://www.medicinaoral.com/odo/volumenes/v7i2/jcedv7i2p278.pdf

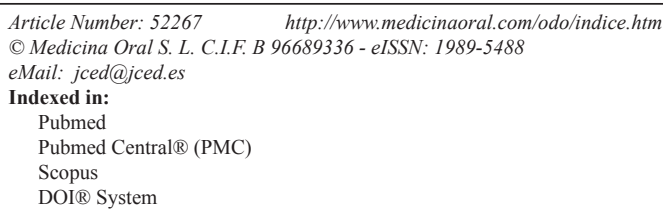

\begin{abstract}
Background: The aim of this in vitro study was to compare the mechanical failure behavior and to analyze fracture characteristics of metal ceramic crowns with two veneering systems - press-on metal (PoM) ceramic versus a conventional veneering system - subjected to static compressive loading.

Material and Methods: Forty-six crowns were constructed and divided into two groups according to porcelain veneer manufacture. Group A: 23 metal copings with porcelain IPS-InLine veneering (conventional metal ceramic). Group B: 23 metal copings with IPS-InLine PoM veneering porcelain. After 120,000 fatigue cycles, the crowns were axially loaded to the moment of fracture with a universal testing machine. The fractured specimens were examined under optical stereomicroscopy and scanning electron microscope.

Results: Fracture resistance values showed statistically significant differences (Student's t-test) regarding the type of ceramic veneering technique ( $p=0.001$ ): Group A (conventional metal ceramics) obtained a mean fracture resistance of $1933.17 \mathrm{~N}$, and Group B 1325.74N (Press-on metal ceramics). The most common type of fracture was adhesive failure (with metal exposure) $(p=0.000)$. Veneer porcelain fractured on the occlusal surface following a radial pattern.

Conclusions: Metal ceramic crowns made of IPS InLine or IPS InLine PoM ceramics with different laboratory techniques all achieved above-average values for clinical survival in the oral environment according to ISO 6872. Crowns made with IPS InLine by conventional technique resisted fracture an average of $45 \%$ more than IPS InLine PoM fabricated with the press-on technique.
\end{abstract}

Key words: Mechanical failure, conventional feldspathic, pressable ceramic, chewing simulator, thermocycling, compressive testing, fracture types, scanning electron microscope. 


\section{Introduction}

Metal ceramic crowns are a treatment that has been and still is - in common use for prosthetic restorations supported by natural teeth or dental implants $(1,2)$.

Although new ceramics such as zirconium oxide offer encouraging expectations in terms of strength and aesthetics, metal-ceramic restorations continue to be the treatment of choice in patients with parafunctional disorders and in posterior areas because of its high mechanical strength and predictability. These restorations enjoy a combination of strength and precision provided by the metal and aesthetics provided by the ceramic coating (3).

Metallic core restorations are usually processed with a conventional veneering system (conventional metal ceramic) but an alternative option is the use of the press-on metal ceramic technique - PoM (pressed-on-metal).

The conventional veneering system takes the metal coping, mechanically coating it with ceramic, which is bonded chemically; the chemical adhesive bond is achieved by sintering. The veneering procedure uses ceramic powders of porcelain composition of different color, mixed to achieve the finished restoration's desired appearance (4).

The press-on metal system has been used successfully for almost two decades for fabricating complete ceramic restorations (3). It can also be used on restorations with metal cores $(5,6)$. The metal coping is fabricated using the same technique but the ceramic veneer is made using a wax-up and a hot press furnace.

The combination of pressing and heat treatment provides a more uniform distribution of the leucite crystals in the glass matrix, providing the porcelain with greater strength (7).

Pressable ceramics are known to possess many desirable properties: the ceramic application technique is simpler and quicker than some of the conventional techniques available, provides acceptable marginal accuracy, and eliminates the need to compensate for the $20 \%$ shrinkage seen with traditional porcelain firing $(8,9)$.

Fracture resistance is the deciding factor for determining the longevity of a restoration in the oral environment. Restorations possessing high fracture resistance have predictably high survival rates under masticatory forces (10-13).

The aim of this study was to assess the mechanical failure behavior of two types of porcelain-veneered crowns with metal core (IPS In-Line conventional feldespathic versus IPS In-Line press-on metal [PoM] [Ivoclar Vivadent, $A G$, Schaan, Liechtenstein]), when subjected to static compressive loading to the point of fracture, and to analyze fracture characteristics by scanning electron microscopy (SEM). The null hypothesis was that the pressed ceramic-to-metal (PoM) system would provide greater fracture resistance than the conventional metal ceramic system.

\section{Material and Methods}

-Study design

The restorations used in this study were fabricated from a master cast, in the form of a maxillary molar of conventional shape, to obtain a full-coverage fixed crown. Forty-six impressions were taken from the master cast using addition silicone (polyvinyl siloxane) of heavy consistency and silicone fluid (Putty and Light Elite $H D{ }^{\circledR}$, Zhermack, Italy) using the double-mix technique. Each impression was then cast in epoxy resin (ExaktoForm ${ }^{\circledR}$, Bredent, Germany). After a 45-minute polymerization, each epoxy resin specimen was removed from the mold and mounted in a 22-mm-diameter copper cylinder, setting the specimen in type IV dental plaster (Pastel Rock Die Stone ${ }^{\circledR}$, Kerr, Italy).

The specimens $(\mathrm{n}=46)$ were divided into two groups according to the veneering porcelain used: Group A - 23 metalceramic crowns with porcelain stratification layering (core: Rexillium V® nickel-chromium alloy, Pentron Laboratory Technologies; porcelain veneer: IPS InLine ${ }^{\circledR}$ ceramic, Ivoclar Vivadent); Group B - 23 metal-ceramic crowns with heat press ceramic (core: Rexillium V® nickel-chromium alloy, Pentron Laboratory Technologies, with porcelain veneer: IPS InLine PoM ${ }^{\circledR}$ ceramic, Ivoclar Vivadent).

The conventional veneer porcelain (IPS-InLine ${ }^{\circledR}$ ) is in the form of a powder/liquid. Its standard composition is: (in $\mathrm{wt} \%$ ) $\mathrm{SiO} 259.5$ - 65.5, Al2O3 13.0 - 18.0, K2O 10.0 - 14.0, Na2O 4.0 - 8.0, Other oxides 0.0 - 4.0; pigments $0.0-2.0$ and its coefficient of thermal expansion (CET) ranges from 12.60 to $13.20 \pm 0.5 \times 10-6 \mathrm{~K}-1$.

The press-on veneer ceramic is in tablet form (ingots) (IPS InLine ${ }^{\circledR}$ PoM). Its standard composition is: (in wt\%) $\mathrm{SiO} 250.0$ - 65.0, $\mathrm{Al} 2 \mathrm{O} 38.0$ - 20.0, Na2O 4.0 12.0, K2O 7.0 - 13.0, other oxides, fluoride 0.0 - 6.0; pigments $0.0-3.0$, and its CET ranges from 13.0 to 13.3 $\pm 0.5 \times 10-6 \mathrm{~K}-1$.

-Crown morphology/design characteristics

The design morphology of each crown followed the molar anatomy from which a wax-up was made. A silicon key was made from the wax-up, with axial thickness of $1 \mathrm{~mm}$ and $1.5 \mathrm{~mm}$ thickness on the occlusal aspect.

The internal crown cap was characterized by two inclined cuspal planes that allowed the porcelain veneer equal thickness over the entire crown surface. In the cervical area, the coping was precisely adjusted to the edge of the restoration piece.

The occlusal anatomy of each crown was designed using the wax-up technique, so that the load applicator of the Instron machine used for the compression tests (a 4-mm aluminum ball) made contact in the fossa of the restoration with three-point contact on the internal slopes of the vestibular cusps and palatine cusp.

Group A: 23 metal copings veneered with IPS-InLine conventional metal ceramics. The first and second dentin firing were carried out according to the manufacturer's 
recommendations. Body porcelain was vibrated and condensed onto the copings. Firing used a Programat PX1 (Ivoclar Vivadent) furnace reaching a final temperature of $929^{\circ} \mathrm{C}$. The anatomy and thickness of the crowns were checked against the silicon key. Lastly, all specimens were finished and glazed conventionally.

Group B: 23 metal copings were veneered with IPS-InLine press-on metal (PoM) ceramic. A wax-up was built on the opaque metal frameworks using ash-free wax (XP Dent Corp., Miami, FL), checking anatomy and thickness. The wax-up was covered with plaster (Gilvest-HS, ICL Business Unit Materials.,Tel-Aviv, Israel) heated and cast (lost-wax technique) in a furnace (Jelrus Tremp-Mastre L two-stage., Buffalo, NY) placing the veneering cylinders and the porcelain ingots selected in the hot press furnace (Programat EP 500, Ivoclar Vivadent), which reached a final temperature of $1075^{\circ} \mathrm{C}$. The porcelain melts and is injected under pressure in the void left by the lost wax inside the veneering cylinder. Afterwards, the specimens were divested, finished, and glazed. This is a simpler and easier technique than that of conventional metal ceramics.

Once fabricated, the crowns were bonded using a dualpolymerization composite resin cement (Multilink ${ }^{\circledR}$ Ivoclar-Vivadent, Liechtenstein). Fatigue loading of each specimen was carried out with a chewing simulator (CS-4.4, thermocycling TC-3; SD Mechatronik, Feldkirchen-Westerham, Germany) producing a total of 120,000 masticatory cycles, with a vertical movement of $2 \mathrm{~mm}$, a frequency of $10 \mathrm{~Hz}$, and a temperature range of $5-55^{\circ} \mathrm{C}^{\circ}$. After fatigue loading simulation, the crowns were subjected to static loading until they fractured.

\section{-Compression testing}

Compression testing was carried out with a mechanical testing machine (Instron ${ }^{\circledR}$ model 4202, MA, USA). The load applicator descended onto the sample exercising continuous vertical force $(5 \mathrm{KN}$ load cell) with a crosshead speed of $0.5 \mathrm{~mm} / \mathrm{s}$, moving vertically downward perpendicular to the occlusal plane. The load force applicator's aluminum ball established three-point contact with the internal slopes of the crown's vestibular cusps and palatine cusp. The machine was stopped once the veneering ceramic had fractured, and the force that had provoked the fracture was measured in Newtons (N). Data were recorded with computer software.

-Statistical analysis

Statistical analysis was performed with SPSS for Windows (SPSS Inc., Chicago, IL, USA). Data were presented as variables of resistance, range, median, means and standard deviations (SD). The Chi-squared test was used to find out whether all the categories of a variable contained the same proportion. Student's t-test was used for the comparison of means between the two veneering ceramics; for dichotomous variables, Fisher's exact test was applied. The significance level was set at $p<0.05$.

-SEM analysis

Firstly, all specimens were examined under an optical stereomicroscope (Leica APO MZ®, Leica Microsystems, IL, USA) with $8 \mathrm{x}$ and $12 \mathrm{x}$ enlargements to identify the type of fracture produced in each sample. When the first observation phase was complete, ten specimens were selected randomly, five from each group, to perform fractography analysis and then composition analysis using SEM. (JEOL JSM 6300 with crystal microanalysis Oxford Instruments Ltd, Tokyo, Japan).

\section{Results}

Results are divided into:

Post-fatigue compressive testing results.

SEM analysis.

1. Post-fatigue compressive test results

1.a. Ceramic fracture resistance values:

Group A (conventional metal ceramic) obtained a mean fracture resistance value of $1933.17 \mathrm{~N}$, while Group B (POM ceramic) obtained $1325.74 \mathrm{~N}$, with Group A values $45 \%$ higher than Group B (Table 1). Student's t-test identified a statistically significant difference in fracture resistance between the groups ( $p=0.001)$ (Fig. 1).

Table 1. Descriptive analysis post-fatigue compressive testing results. Group A (conventional metal ceramic), group B (pressed-on-metal ceramic). Fracture resistance values in Newtons.

\begin{tabular}{|c|c|c|c|c|}
\hline & & Porcelain & & \\
\hline & & Total & Group A & Group B \\
\hline & Valid Number & 46 & 23 & 23 \\
\hline & Average & 1629,46 & 1933,17 & 1325,74 \\
\hline LOAD (N) & Standard Deviation & 588,28 & 619,26 & 364,24 \\
\hline & Minimum & 790,89 & 944,71 & 790,89 \\
\hline & Median & 1601,00 & 1907,99 & 1253,99 \\
\hline & Maximum & 2819,01 & 2819,01 & 1931,99 \\
\hline
\end{tabular}




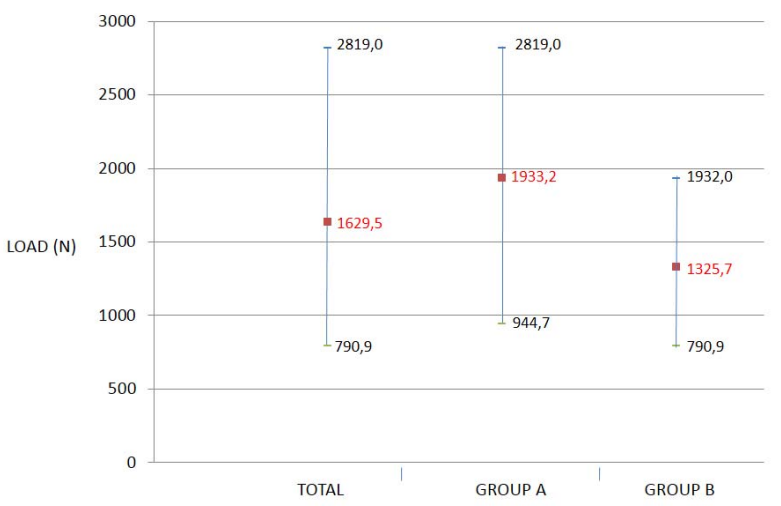

Fig. 1. The difference between means of the tested groups A and B are represented. Group A (conventional metal ceramic) 45\% higher than group B (pressed-on-metal ceramic) with a statistically significant difference.

\section{1.b. Fracture type}

The most commonly occurring type of fracture among the crowns was adhesive $(\mathrm{n}=38)$; only eight crowns suffered cohesive fracture, with statistically significant difference identified by the chi-squared test $(p=0.00)$. However, comparing the two techniques by means of the Fisher test revealed a $p$-value of 0.500 , and so no difference in fracture type.

2. SEM analysis

SEM microphotos show the crowns' (occlusal) fracture zones and how fractures followed a radial or peripheral pattern; in other words, veneer porcelain deformation was produced in the occlusal area, producing a fracture of radial shape (Fig. 2).

SEM examination (250x magnification) of transversal sections of the crowns revealed the characteristics of the different parts in detail: the metal layer with its characteristic nickel texture, the opaque layer above (with bubbles visible in Group B) and the surface veneering porcelain (Fig. 3a,b).

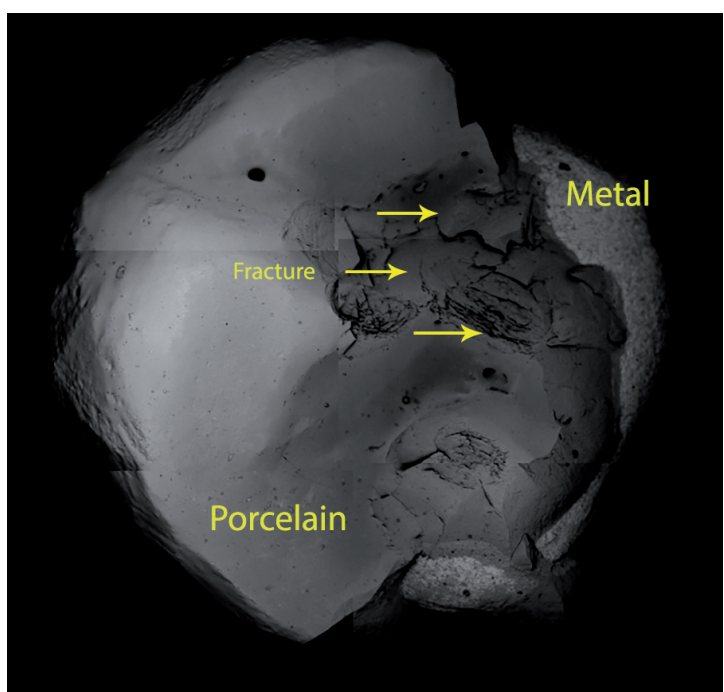

Fig. 2. Type of adhesive fracture with metal exposure.
Fracture followed a course characteristic of adhesive fracture, from the surface porcelain towards the layer of opaque and from this layer to the metal, exposing the metal core (Fig. 4).
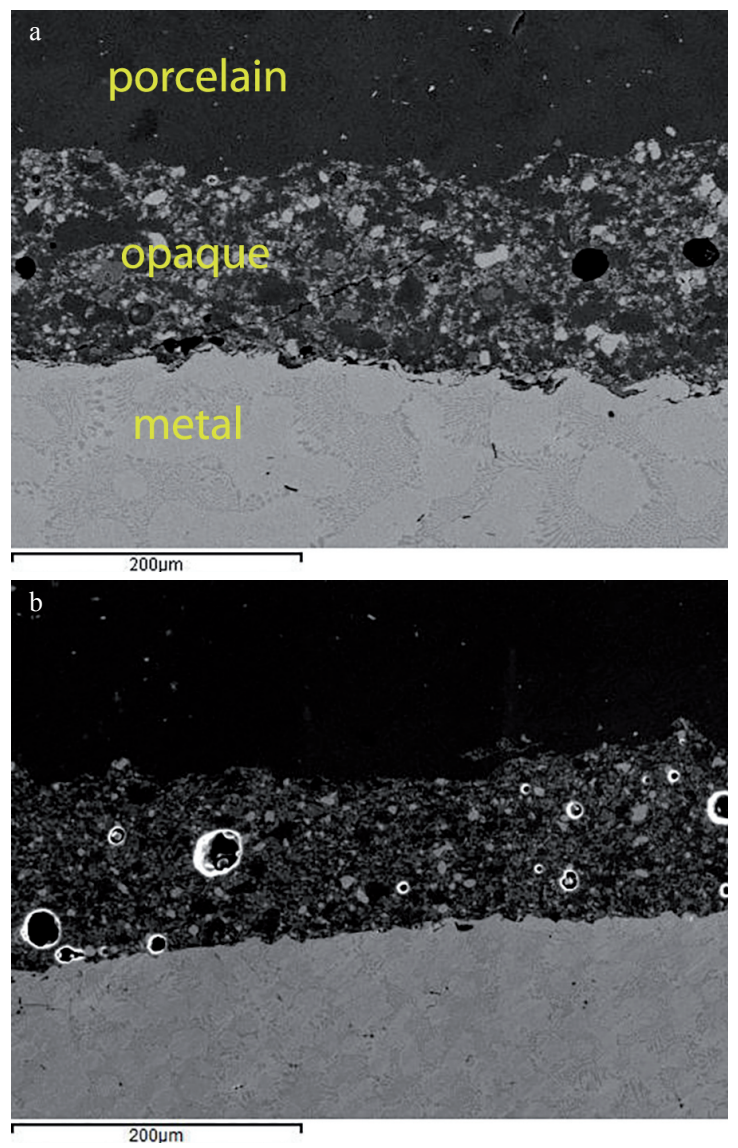

Fig. 3. SEM 250x. a) Group A conventional metal ceramic. b) Group B pressed-on-metal ceramic. Microphotos revealed the characteristics of the different parts: the metal layer, the opaque layer (greater incidence of porosities in Group B and the surface porcelain.

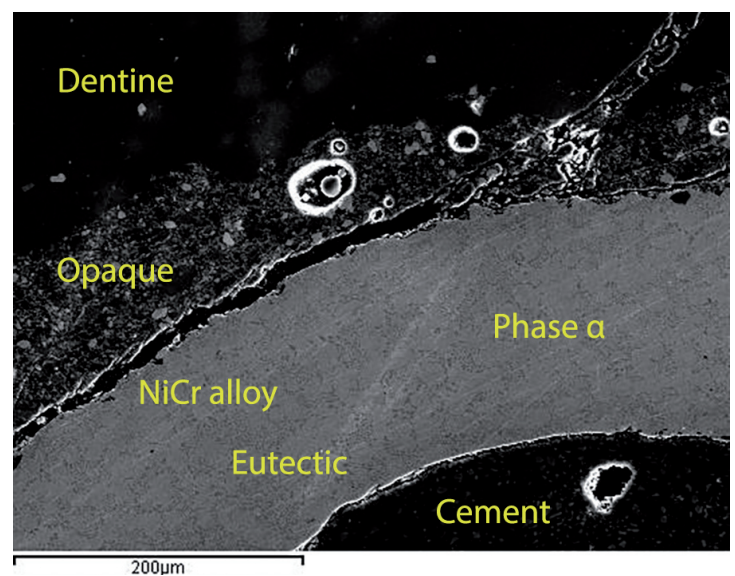

Fig. 4. SEM 250x examination of transversal sections of a crown of group B. It reveals the characteristic path of an adhesive fracture (yellow arrow), from the porcelain surface towards the layer of opaque and from this layer to the metal, exposing the metal coping. 
2.b SEM analysis of porcelain composition

When the compositions of the veneer porcelains in each test group were analyzed by SEM (Energy dispersive $\mathrm{x}$-ray analysis at an electron voltage de $20 \mathrm{kV}$ ), both porcelains showed identical compositions, of the same elements with slight variations in percentages.

Mean values found were: $\mathrm{SiO} 2$ 64.32, $\mathrm{Al} 2 \mathrm{O} 3$ 13.62, $\mathrm{K} 2 \mathrm{O} 7.51, \mathrm{Na} 2 \mathrm{O} 7.70$ in Group A, and $\mathrm{SiO} 256.88$, Al2O3 12.49, K2O 11.84, Na2O 4.95 in Group B (Fig. 5). These values are corroborated by the data supplied by the manufacturers (Ivoclar $\left.{ }^{\circledR}\right)$.
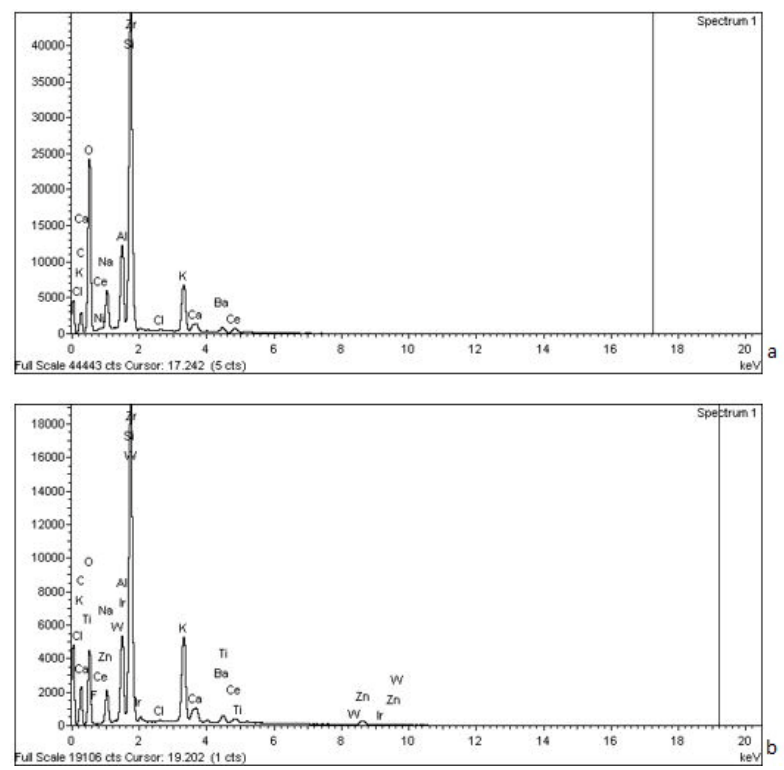

Fig. 5. Chemical compositions of the veneer porcelains in each test group using SEM 500x. Values group A (a) and group B (b).

\section{Discussion}

-Methodology

The choice of strength test type and design - compressive testing in this case - was based on Clinical Research Associates (CRA) recommendations for studying the resistance of ceramic materials. 10 Other features of the study - study design, sample preparation, number of samples, loading speed, etc.- were similar to methods proposed by various other authors $(12,13)$. According to the literature, pure compression testing would appear adequate for fracture resistance testing of crown and bridges (14-18). Before compression testing, samples were subjected to an ageing process as suggested by various authors $(1,5,11)$.

Sample design in the present study took an upper first molar at 1:1 scale as real size offers results that are as close as possible to clinical reality, results were expressed as Newtons (N) $(10,19,20)$.

-Results

The mean fracture resistance value for Group A conventional metal ceramic was 1933.17 N. Similar stu- dies have also used real size metal-ceramic crowns and compression testing with the universal testing machine, obtaining results ranging from $1680 \mathrm{~N}$ to $2335.16 \mathrm{~N}$ (3,10,19-24).

The results obtained greater fracture resistance for the conventional metal ceramic samples (1933.17 N), while the PoM press-on metal ceramic obtained 1325.74 N. Student's t-test identified a statistically significant difference in fracture resistance between the groups $(p=0.001)$. In this way, the null hypothesis - that the pressed ceramic-to-metal (POM) system would provide greater fracture resistance than the conventional metal ceramic system - was rejected.

Other researchers have carried out similar studies with differing results. A study by Fahmy (21) obtained higher values with PoM, obtaining 2025.6N, while the conventional technique obtained $1810.3 \mathrm{~N}$.

Schweitzer (22) found no significant differences when comparing the bond strength of a pressed ceramic fused to metal compared with feldspathic porcelain fused to metal. Likewise, Venkatachalam et al. (4) made a comparative study of bond strength but did not observe significant differences in the mean fracture resistance of ceramic pressed to metal compared to feldspathic porcelain fused to metal.

The most commonly observed fracture types were adhesive fracture, a finding that coincides with studies by Alhasanyah (1) and Blatz (11). Agustín (10) also analyzed the mechanical behavior of four groups of crowns subjected to static loading - three types of zirconia crown and one metal-ceramic (IPS d.SIGN, Ivoclar Vivadent) finding that $100 \%$ of the metal-ceramic crowns suffered adhesive fractures. However, Marker (19) observed a higher rater of cohesive fractures (under macroscopy).

-Scanning electron microscope analysis (SEM)

Konstantinos (24) studied the fracture resistance of metal-ceramic restorations, analyzing samples by SEM after loading, observing a radial fracture pattern around the loaded area. The present study observed the same radial or peripheral fracture pattern, which coincides with other authors' observations $(10,25,26)$.

The present study also noted a higher number of porosities and design imperfections in the porcelain veneers produced by the press-on technique (PoM) than with stratified ceramics, which might explain the different mechanical behavior observed in the study; Venkatachalam et al. (4) obtained similar findings under microscopy. In contrast to the study Drummond (7).

\section{Conclusions}

The metal-ceramic crowns made with IPS InLine ceramics and IPS InLine PoM with different laboratory techniques achieved above-average values for clinical survival in the oral environment in accordance to ISO 6872. Crowns made using the conventional IPS InLine tech- 
nique showed $45 \%$ greater fracture resistance than IPS InLine PoM made with the press-on technique.

Veneer porcelain fractures in the occlusal contact area and the fracture displays a radial pattern.

The most common type of fracture is adhesive failure (with metal exposure).

\section{References}

1. Alhasanyah A, Vaidyanathan TK, Flinton RJ. Effect of Core Thickness Differences on Post-Fatigue Indentation Fracture Resistance of Veneered Zirconia Crowns. J Prosthodont. 2013;22:383-90.

2. Christensen G. Porcelain fused to metal versus zirconia based ceramic restorations. J Am Dent Assoc. 2009;140:1036-9.

3. Charles E. Compressive strengths of a new foil and porcelain-fusedto-metal crowns. J Prosthet Dent. 1987;57:404-10.

4. Venkatachalam B, Goldstein GR, Pines MS, Hittelman EL., Ceramic pressed to metal versus feldspathic porcelain fused to metal: a comparative study of bond strength. Int J Prosthodont. 2009;22:94-100.

5. Kim B, Zhang Y, Pines M, Thompson VP. Fracture of porcelainveneered structures in fatigue. J Dent Res. 2007;86:142-6.

6. Schweitzer DM, Goldstein GR, Ricci JL, Silva NR, Hittelman EL. Comparison of bond strenght of a pressed ceramic fused to metal versus feldspathic porcelain fused to metal. J Prosthodont. 2005;14:23947.

7. Drummond JL, King TJ, Bapna MS, Koperski RD. Mechanical property evaluation of pressable restorative ceramics. Dent Mater. 2000;16:226-33.

8. Goldin EB, Boyd NW, Goldstein GR, Hittleman EL, Thompson VP. Marginal fit of leucite-glass pressable ceramic restorations and ceramic-pressed-to-metal restorations. J Prosthet Dent. 2005;93:143-7.

9. Grossman DG. Cast glass ceramics. Dent Clin North Am. 1985;29:725-39.

10. Agustín-Panadero R, Fons-Font A, Román-Rodriguez JL, GranellRuíz M, del Rio-Highsmith J, Solá-Ruíz MF. Zirconia Versus Metal: A Preliminary Comparative Analysis of Ceramic Veneer Behavior. Int J Prosthodont. 2012;25:294-300.

11. Blatz MB, Bergler M, Ozer F, Holst S, Phark JH. Bond strength of different veneering ceramics to zirconia and their susceptibility to thermocycling. Am J Dent. 2010;23:213-6.

12. Snyder MD, Hogg KD. Load-to-fracture value of different allceramic crown Systems. J Contemp Dent Pract. 2005;6:54-63.

13. Bindl A, Lüthy H, Mörmann H .Thin-wall ceramic CAD/CAM crown copings: strength hand fracture pattern. J Oral Rehabil. 2006;33:520-8.

14. Eisenburger M, Mache T, Borchers L, Stiesch M. Fracture stability of anterior zirconia crowns with different core designs and veneered using the layering or the press-over technique. Eur J Oral Sci. 2011;119:253-7.

15. Heintze S, Cavalleri A, Zellweger G, Büchler A, Zappini G. Fracture frequency of all-ceramic crowns during dynamic loading in a chewing simulador using different loading and luting protocols. Dent Mater. 2008;24:1352-61.

16. Jörn D, Waddell N, Swain M. The influence of opaque application methods on the bond strength and final shade of PFM restorations. J Dent. 2010;38:143-9.

17. Salazar S, Studart A, Bottino M, Della Bona A. Mechanical strenfth and subcritical crack growth under wet cyclic loading of glassinfiltrated dental ceramics. Dent Mater. 2010;26:483-90.

18. Zhang D, Lu C, Zhang X, Mao S, Arola D. Contact fracture of fullceramic crowns subjected to occlusal loads. J Biomech. 2008;4:29953001 .

19. Marker J, Goodkind R, Gerberich W. The compressive strength of nonprecious versus precious ceramometal restorations with various frame designs. J Prosthet Dent. 1986;55:560-7.

20. Brukl C, Ocampo R. Compressive strengths of a new foil and porcelain-fused-to-metal crowns. J Prosthet Dent. 1987;57:404-10.

21. Fahmy NZ, Salah E. An in vitro assessment of a ceramic-pressed- to-metal system as an alternative to conventional metal ceramic systems. J Prosthodont. 2011;20:621-7.

22. Schweitzer D, Goldstein G, Ricci J, Hittelman E. Comparison of bond strength of a presser ceramic fused to metal versus feldspathic porcelain fused to metal. J Prosthodont. 2005;14:239-47.

23. Kellerhoff R, Fischer J. In vitro fracture strength and thermal shock resistance of metal-ceramic crowns with cast and machined AuTi frameworks. J Prosthet Dent. 2007;97:209-15.

24. Konstantinos X, Athanasios S, Hirayama H, Kiho K, Foteini T, Yukio O, Fracture resistance of metal ceramic restorations with two different margin designs after exposure to masticatory simulation. J Prosthet Dent. 2009;102:172-8.

25. Tsalouchou E, Cattell M, Knowles J, Pittayachawan P, McDonald A. Fatigue and fracture properties of yttria partially stabilized zirconia crown systems. Dent Mater. 2008;24:308-18.

26. Shijo Y, Shinya A, Gomi H, Lassila L, Vallittu P, Shinya A. Studies on mechanical strength, thermal expansion of layering porcelains to alumina and zirconia ceramic core materials. Dent Mater. 2009;28:352-61.

\section{Acknowledgements}

The authors acknowledge the support of VLC/CAMPUS Valencia, International Campus of Excellence, Microcluster de Biomateriales Odontologicos Program. They also thank Prof. Dr. Vicente Amigó Borrás, Director of the Institute of Materials Technology, for his technical support throughout the development of this study and Ivoclar Vivadent for their assistance. 